International Review of Research in Open and Distributed Learning Volume 16, Number 3

June -2015

\title{
Massive Open Online Course Completion Rates Revisited: Assessment, Length and Attrition
}

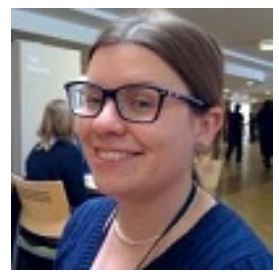

Katy Jordan

The Open University, UK

\begin{abstract}
This analysis is based upon enrolment and completion data collected for a total of 221 Massive Open Online Courses (MOOCs). It extends previously reported work (Jordan, 2014) with an expanded dataset; the original work is extended to include a multiple regression analysis of factors that affect completion rates and analysis of attrition rates during courses. Completion rates (defined as the percentage of enrolled students who completed the course) vary from $0.7 \%$ to $52.1 \%$, with a median value of $12.6 \%$. Since their inception, enrolments on MOOCs have fallen while completion rates have increased. Completion rates vary significantly according to course length (longer courses having lower completion rates), start date (more recent courses having higher percentage completion) and assessment type (courses using auto grading only having higher completion rates). For a sub-sample of courses where rates of active use and assessment submission across the course are available, the first and second weeks appear to be critical in achieving student engagement, after which the proportion of active students and those submitting assessments levels out, with less than $3 \%$ difference between them.
\end{abstract}

Keywords: Distance education; open learning; online learning; massive open online courses (MOOCs) 


\section{Introduction}

Since Massive Open Online Courses (MOOCs) became mainstream in 2012, completion rates have been a controversial topic. While six-figure enrolment figures have garnered intense media attention, critics have highlighted that few students complete courses relative to more formal modes of learning. Counter to this, others have argued that the emancipatory effect of free online access to education allows students to take what they need from MOOCs to meet their own learning goals without formally completing courses; to examine completion rates is potentially misleading (LeBar, 2014). This study takes a perspective which acknowledges that while completing courses is not the only way of benefitting from participation in a MOOC, it is better to try to understand the factors that affect completion rates and any implications for course design than to ignore them.

In the literature on MOOCs there is a lack of peer-reviewed research publications which draw upon more than a small number of courses restricted to single institutions, and the need for metaanalysis independent of MOOC platform providers is a key issue for the field at present. For example, Kizilcec, Piech and Schneider (2013) identified learner populations based on analysis of three early Coursera MOOCs; replication of this analytical approach on data from the Futurelearn platform identified different groups (Ferguson \& Clow, 2015). Enrolment and completion figures are the type of data that is most widely publicly available for analysis across the field, which is necessary to ensure that conclusions are generalisable and not particular to a small number of detailed cases.

Understanding the factors which affect completion rate can be approached from the perspective of characteristics of learners and their reasons for participating, or improving the design of courses. Greater focus to date has been on the motivations and behaviours of students in relation to success (for example, Breslow et al., 2013; Kizilcec et al., 2013; Koller, Ng, Do \& Chen, 2013; Rosé et al., 2014). However, studies have suggested that those most likely to succeed in MOOCs are the students who are already most educationally privileged (Emanuel, 2013; Koller and Ng, 2013). Addressing MOOC completion rates from a course design perspective, in order to help as many diverse learners to complete as would wish to, is a pedagogical issue and a challenge for course designers and instructors. In order for MOOCs to realise their potential in making education open to all, it is not sufficient to simply make pre-existing course materials freely available online. Completion rates are relatively low even among students who intend to complete the course (an average of 22\%; Reich, 2014) so for those students who intend to complete courses or engage with the course as designed, not considering completion rates prevents exploration of what can be done by educators to facilitate further student success.

This paper reports work undertaken to extend a previous study on initial trends in MOOC completion rate (J ordan, 2014), which remains one of the largest MOOC studies in terms of number of courses included. The dataset is expanded (to include more recent data, and not

This work is licensed under a Creative Commons Attribution 4.0 International License. 
restricted to the major MOOC providers) and multiple regression analysis is used to explore the combined effects of a range of basic factors in correlation to completion rate. Additionally, quantitative measures of engagement across the course of a MOOC are examined in instances where this data is available.

\section{Data Collection and Analysis}

The approach to data collection built upon an initial dataset (reported in Jordan, 2014) which combined enrolment and completion figures from news stories, MOOCs the author had taken as a participant, and crowdsourced figures submitted by other students and MOOC instructors via a blog. In order to expand the dataset, the author compiled a list of completed MOOCs not present in the original dataset (based on in formation from MOOC-aggregating websites such as https://www.class-central.com/) and performed a series of Internet searches to find sources containing enrolment and completion information for the courses. Information was found and included relating to a total of 221 MOOCs. Information about $35.3 \%$ of the courses was located in news articles; $33.6 \%$ were sourced from academic reports and articles; $14.5 \%$ from instructors' social media; $9.9 \%$ from students' social media; and 6.8\% from course sites. Further information about courses, including course length and assessment type, was gathered via signing up to the courses, asking participants or consulting MOOC-aggregating websites. Information about university reputation was included based on the scores used by the Times Higher Education World University Rankings (Times Higher Education, 2013). No further courses were added to the dataset after November 2013. To access the full dataset, including links to each source and further recent additions, see the online data visualization (J ordan, 2015). The dataset can be summarised as follows:

- A total of 221 courses were included in the dataset. Within this sample, enrolment figures were available for 220 courses; completion figures were available for 129 courses; and figures relating to engagement over the course of a MOOC were available for 59 courses. The two most common definitions of engagement across the duration of courses used by the sources were the number of students accessing resources, or completing assignments.

- Courses from a range of different MOOC providers were included. Coursera (120 courses) and Open2Study (43 courses) were the best represented platforms, although courses from 12 other providers and 19 independent courses were also included. A total of 78 institutions were present in the dataset.

- A variety of different definitions of completion are in operation. Of the 129 courses for which completion data was available, the most prevalent definition of completion was earning a certificate (93 courses). Other definitions (as used by their data sources) 
included 'completed course' (14 courses), 'passed course' (10 courses), 'completed assignments' (6 courses), 'memorably active participants', achieving a 'strong final score', active contributors at end of course, certificates purchased, kept up' with whole course, or 'took final exam' (1 course each).

- In addition to enrolment and completion figures, other data collected about courses included start date, length of course (in weeks), and assessment type used. Assessment type was categorised using three basic categories: auto grading only (92 courses), peer grading only (10 courses), or a combination of both auto and peer grading (23 courses).

Three types of analysis were applied to the dataset. Since the expanded dataset encompassed a wider time period, linear regression analysis was used to gain an overview of whether MOOC enrolments and completion rates were changing over time.

Multiple regression analysis was then used with a sub-sample of courses to explore whether MOOC completion rates are significantly correlated with a range of factors. Multiple regression is "an extension of simple regression in which an outcome is predicted by two or more predictor variables" (Field, 2009, p. 790). As an analytical approach, multiple regression offers the advantage of being able to examine the relationship between multiple variables upon an outcome (in this case, completion rate). The factors examined included assessment type, course length, date, and university ranking score. While course length, date and university ranking had previously been examined individually (J ordan, 2014), the larger dataset offered the opportunity to consider the factors together. Platform and MOOC type were not included due to wide variation in sample sizes. Note that full information about all of the factors was not available for every course in the sample, so not all of the courses in the dataset were used in the regression analysis (see results and discussion). The statistical analyses were undertaken using SPSS (Field, 2009).

The third type of analysis focused upon a smaller sample of courses for which data was available about number of students participating week-by-week across the course of live MOOCs. In some cases, raw data was not available and required extraction from charts using software (Rohatgi, 2014). This extends the original finding that approximately fifty percent of potential MOOC students who sign up go on to become active users (J ordan, 2014) and examine how this trend progresses. Participation is defined in two ways by data sources: either the number of students viewing course materials, or the number submitting assignments. To allow comparison, these values were expressed as a percentage of the total enrolment for each course. The resulting curves were compared visually and average curves constructed using mean values. 


\section{Results}

The first analyses focused upon whether enrolments and completion rates appeared to be changing over time. Regression analysis was performed to examine the extent to which course start date predicts the number of students enrolled (figure 1), and the extent to which course start date predicts the percentage of students that complete the course (figure 2). Prior to both analyses, a Box-Cox transformation was applied as the residuals were not normally distributed. Date significantly predicted total enrolment figures by the following formula: Enrolled ${ }^{`} 0.180902$ $=66.3311-0.00147092$ Date $(n=219, \mathrm{R} 2=0.0252, \mathrm{p}=0.019)$. Note that the correlation here is negative; as time has progressed, the size of the average MOOC has decreased. Date also significantly predicted completion rate by the following formula: PercentCompleted $0.5=$ $152.428+0.00377601$ Date $\quad(n=129, \mathrm{R} 2=0.1457, \mathrm{p}<0.001)$. In contrast, this represented a positive correlation, so while total enrolments have decreased, completion rates have increased over time.

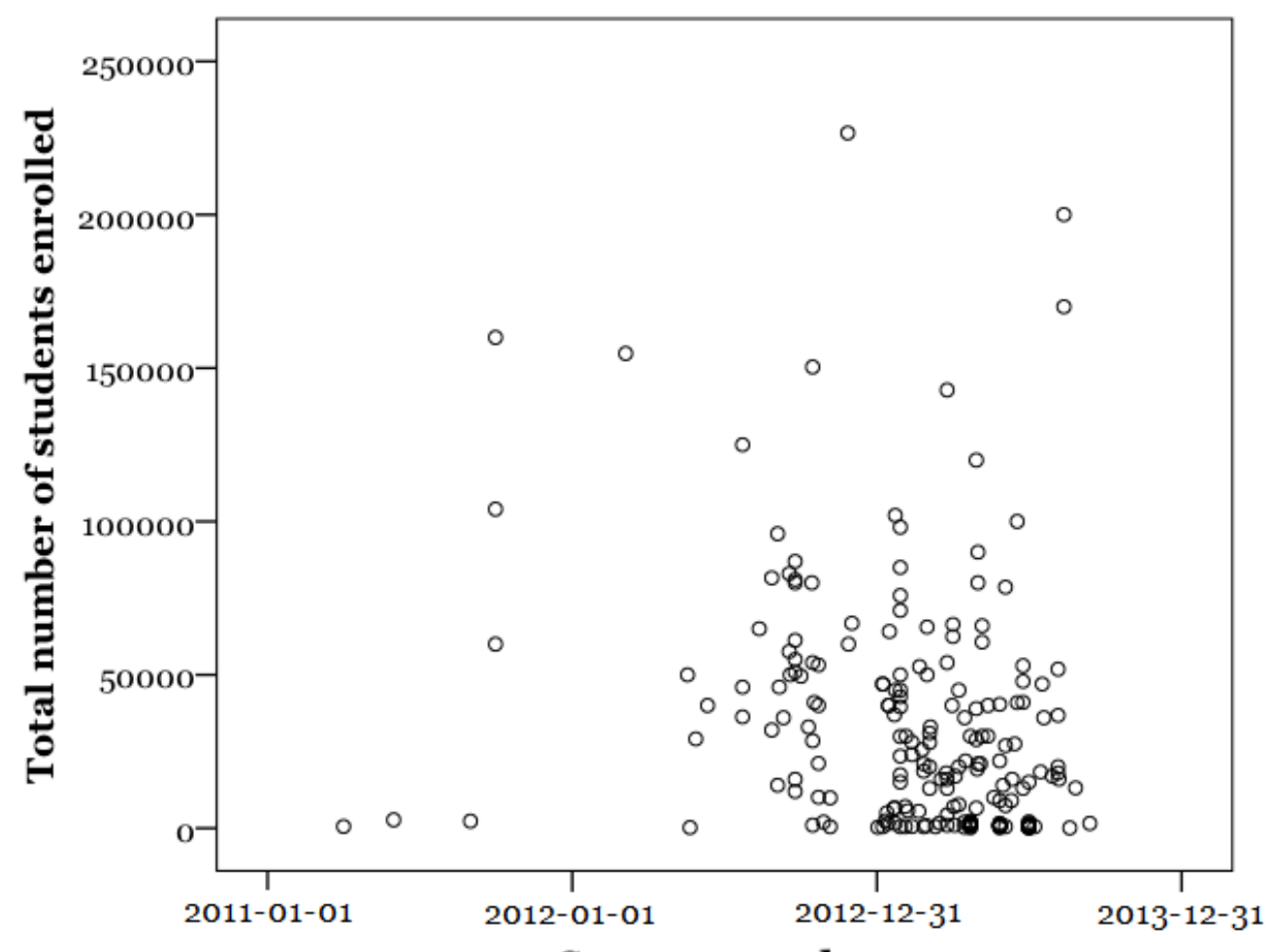

Course start date

Figure 1. Scatterplot of MOOC course enrolments plotted against course start date ( $n=219)$. 


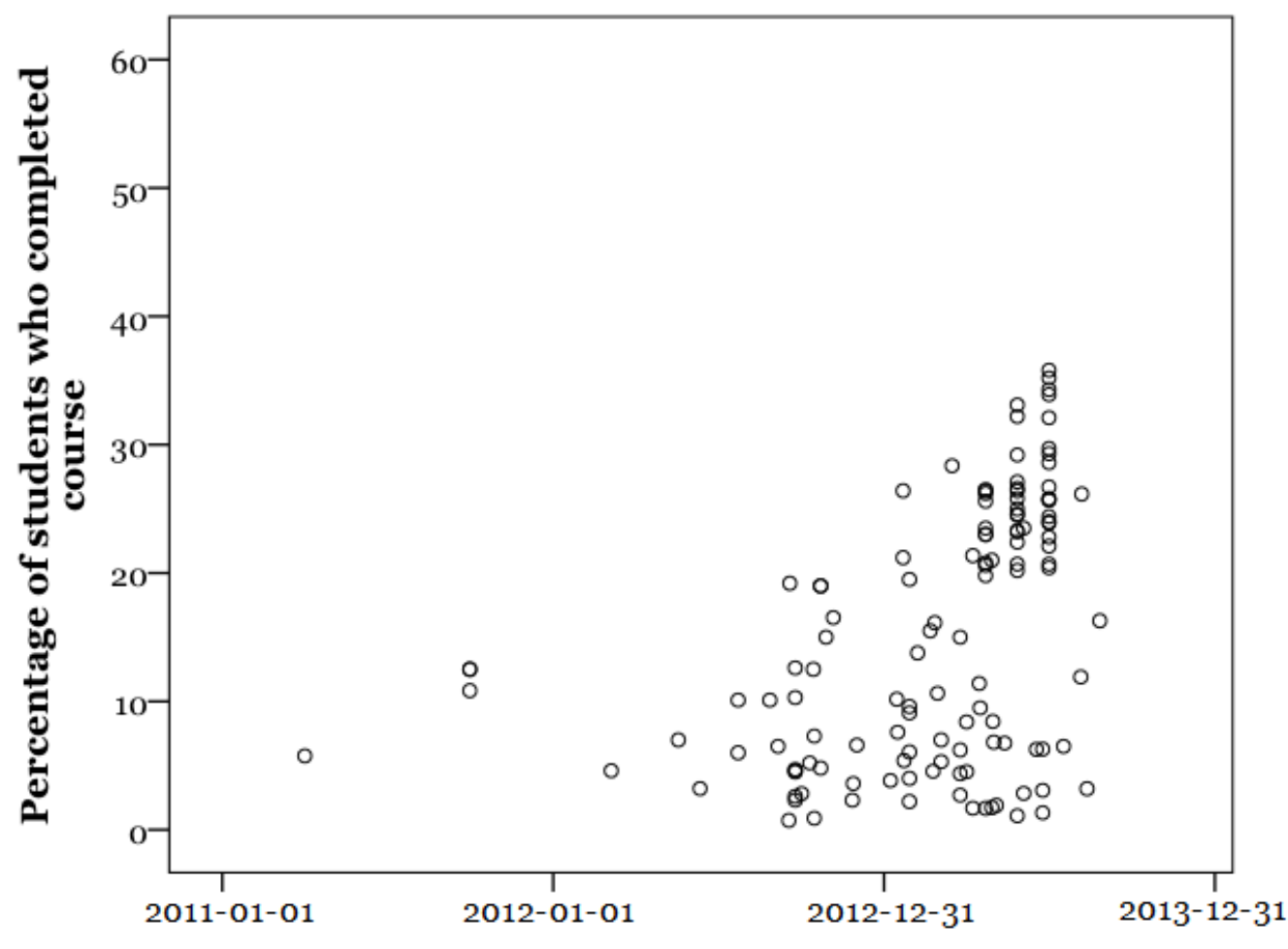

Course start date

Figure 2. Scatterplot of percentage of students who completed courses plotted against course start date $(n=129)$.

\section{Multiple Regression Analysis}

A multiple regression analysis was carried out in order to examine the combined effects of the factors upon completion rate, which had previously been examined individually (J ordan, 2014). An initial run of the analysis included the following factors: University ranking score, start date, course length (in weeks), total number of students enrolled, and assessment type. Assessment type was a categorical variable comprising three categories ('Auto grading only', 'peer grading only', and 'auto and peer grading'). The start date variable was defined as the date that each course formally launched; for the purposes of the analysis, this information was converted to the Lilian date format. The result of this initial analysis showed that while the model explained a significant amount of the variance in completion rate $\left(F(6,53)=13.98, p<.05, R^{2}=.61, R^{2}\right.$ Adjusted $=.57$ ), not all of the factors significantly predicted completion rate. In light of this, university ranking and total enrolment were excluded from the analysis, and assessment types recoded into two categories based on whether or not peer grading was used at all.

The analysis proceeded to examine the extent to which start date, course length and use of peer grading predicted completion rate. An analysis of standard residuals was carried out, which 
showed that the data contained no outliers (Std. Residual Min $=-2.56$, Std. Residual Max =2.07). Tests to see if the data met the assumption of collinearity indicated that multicollinearity was not a concern (course length, Tolerance $=.96, \mathrm{VIF}=1.40$; start date, Tolerance $=.99$, VIF $=1.01$; use of peer grading, Tolerance $=.96, \mathrm{VIF}=1.05$ ). The data met the assumption of independent errors (Durbin-Watson value $=1.08$ ). The histogram of standardised residuals indicated that the data contained approximately normally distributed errors, as did the normal P-P plot of standardised residuals. The scatterplot of standardised predicted values showed that the data met the assumption of linearity but may have violated the assumption of homoscedasticity. Note that violating this assumption does not invalidate the analysis, which is accurate based upon the sample used, but reduces the likelihood that the model generalises to the population (this would not be certain, but more likely, if all the assumptions were met; Field, 2009). The heteroscedasticity observed is not severe and is most likely caused by the presence of significant variables that are not included in the model. Given the opportunistic nature of the data collection it would be surprising if all significant variables had been identified. However, this does not detract from the significant factors that have been determined. The data also met the assumption of non-zero variances (course length, Variance $=13.58$; start date, Variance $=15480621$.9; use of peer grading, Variance $=.195)$.

Using the enter method it was found that course length, start date and use of peer grading explain a significant amount of the variance in the completion rate $\left(F(3,117)=57.7, p<.05, R^{2}=.60\right.$, $\mathrm{R}^{2}$ Adjusted $=.59$ ). The model summary, ANOVA table and coefficients table from the analysis are shown in tables 1,2 and 3, respectively.

Table 1

Model Summary

Model Summaryb

\begin{tabular}{|l|l|l|l|l|l|}
\hline Model & $\mathrm{R}$ & $\begin{array}{l}\mathrm{R} \\
\text { Square }\end{array}$ & Adjusted R Square & $\begin{array}{l}\text { Std. Error of the } \\
\text { Estimate }\end{array}$ & Durbin-Watson \\
\hline 1 & $\begin{array}{l}.773 \\
\mathrm{a}\end{array}$ & .597 & .587 & 6.905697235734618 & 1.084 \\
\hline
\end{tabular}

a. Predictors: (Constant), PeerGrading, DateISO, Length

b. Dependent Variable: PercentCompleted 
Table 2

ANOVA Table

ANOVAa

\begin{tabular}{|ll|l|l|l|l|l|}
\hline \multicolumn{2}{|l|}{ Model } & Sum of Squares & $\mathrm{df}$ & $\begin{array}{l}\text { Mean } \\
\text { Square }\end{array}$ & $\mathrm{F}$ & Sig. \\
\hline \multirow{2}{*}{1} & Regression & 8260.829 & 3 & 2753.610 & 57.741 & $.000^{\mathrm{b}}$ \\
& $\begin{array}{l}\text { Residual } \\
\text { Total }\end{array}$ & 5579.573 & 117 & 47.689 & & \\
& 13840.402 & 120 & & & \\
\hline
\end{tabular}

a. Dependent Variable: PercentCompleted

b. Predictors: (Constant), PeerGrading, DateISO, Length

Table 3

Coefficients Table

\section{Coefficients}

\begin{tabular}{|c|c|c|c|c|c|c|c|c|}
\hline \multirow{2}{*}{\multicolumn{2}{|c|}{ Model }} & \multicolumn{2}{|c|}{$\begin{array}{l}\text { Unstandardised } \\
\text { Coefficients }\end{array}$} & \multirow{2}{*}{$\begin{array}{l}\text { Standardised } \\
\text { Coefficients } \\
\text { Beta }\end{array}$} & \multirow[t]{2}{*}{$\mathrm{t}$} & \multirow[t]{2}{*}{ Sig. } & \multicolumn{2}{|c|}{$\begin{array}{l}\text { Collinearity } \\
\text { Statistics }\end{array}$} \\
\hline & & $\mathrm{B}$ & $\begin{array}{l}\text { Std. } \\
\text { Error }\end{array}$ & & & & $\begin{array}{l}\text { Toleran } \\
\text { ce }\end{array}$ & VIF \\
\hline \multirow{5}{*}{1} & (Constant) & 57.38 & 5.029 & & 11.4 & .000 & & \\
\hline & & -.001 & .000 & -.343 & & .000 & .991 & 1.009 \\
\hline & DateISO & & & & $\begin{array}{l}5.81 \\
6\end{array}$ & & & \\
\hline & Length & -1.751 & .209 & -.503 & $-\overline{8} 39$ & .000 & .958 & 1.043 \\
\hline & $\begin{array}{l}\text { PeerGradi } \\
\text { ng }\end{array}$ & 9.606 & 1.472 & -.392 & $\begin{array}{l}- \\
6.52 \\
7\end{array}$ & .000 & .955 & 1.047 \\
\hline
\end{tabular}

a. Dependent Variable: PercentCompleted 
The correlation between start date and completion rate was positive, in that completion rates increased over time. The other factors - course length and whether or not peer grading was used - were both negative correlations (Figures 3 and 4), with longer courses and those which use peer grading having lower completion rates than shorter or auto-graded courses.

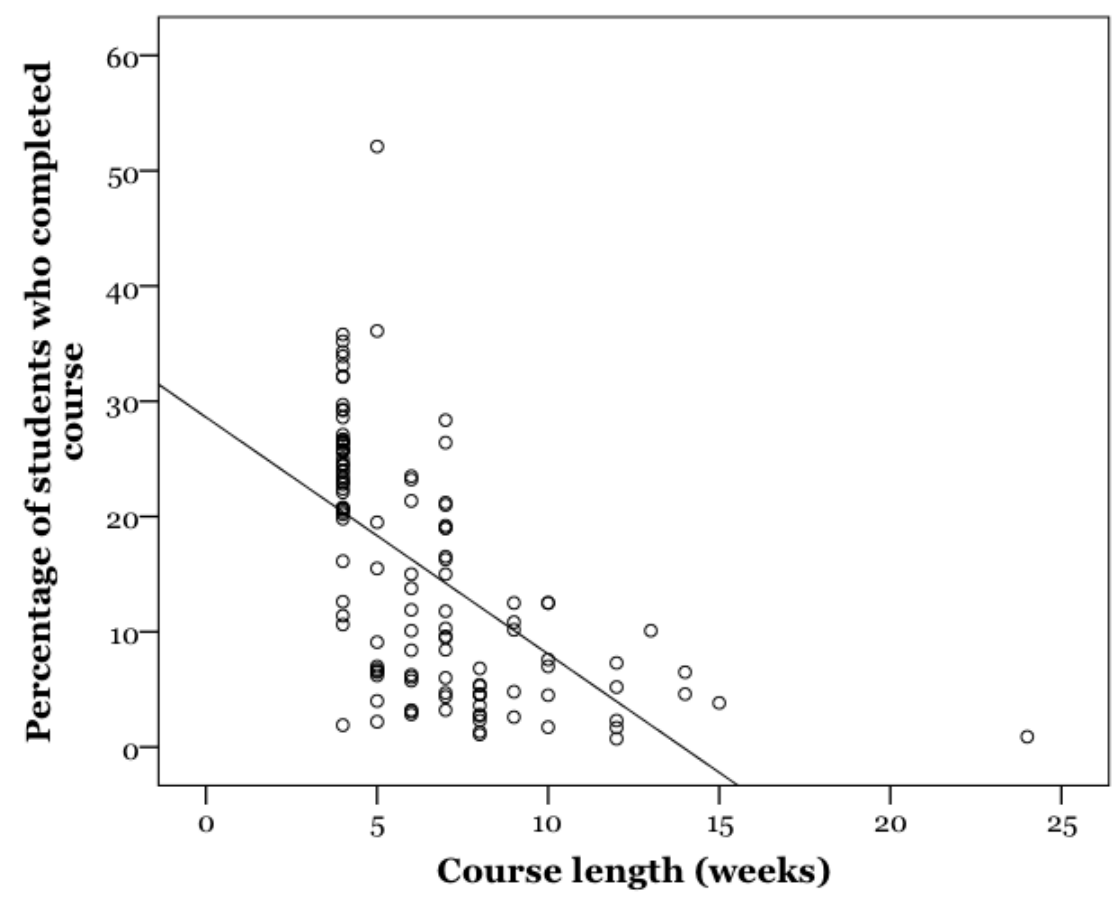

Figure 3. Completion rate plotted against course length in weeks. 


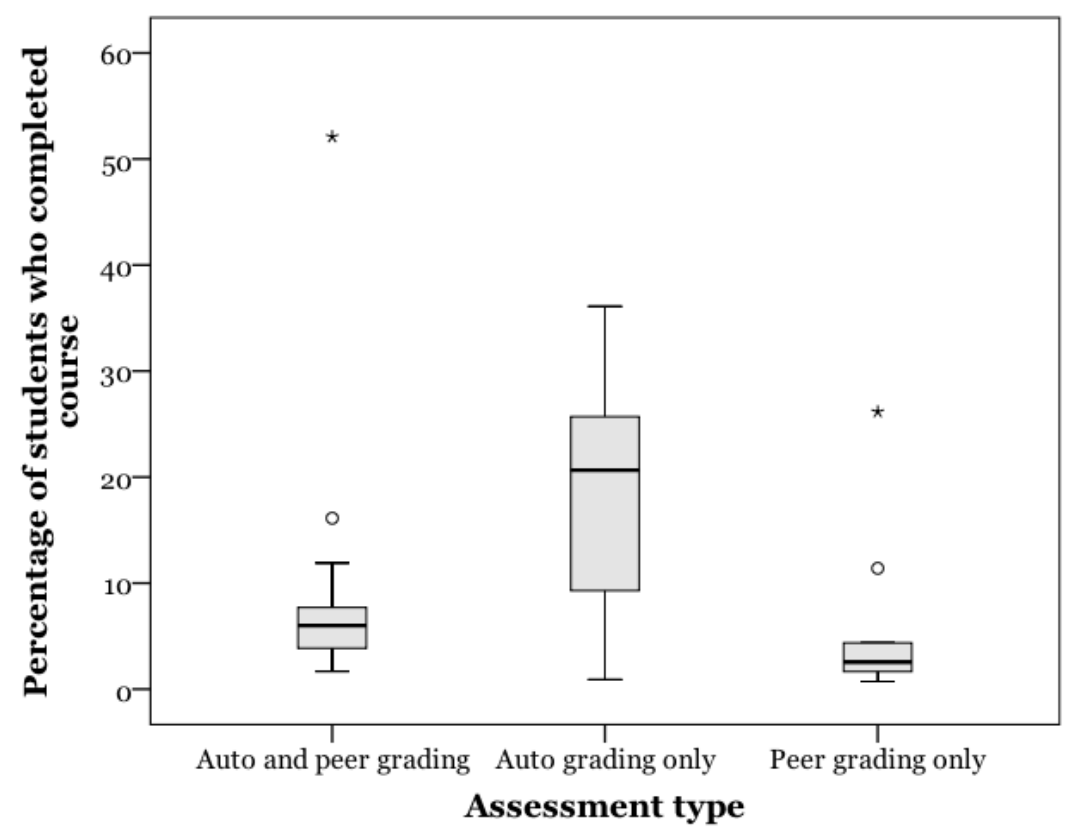

Figure 4. Boxplots showing distributions of completion rates according to different assessment types.

This categorization is not elaborate and, with an $\mathrm{R}^{2}$ of $60 \%$, a reasonable proportion of the variance remains unexplained, It does however demonstrate that it is possible to gain insights into the impact of learning design decisions by considering completion rate. Availability of data is an obstacle to further detailed analyses (such as considering the use of exams, different forms of auto and peer grading, formative or summative assessment) at this stage.

\section{Attrition Rates During Live Courses}

The previous study considered the conversion rate between students who enrol and then go on to become active in courses, by accessing course materials or logging in to the course site (J ordan, 2014). This part of the analysis sought to extend this by considering the levels of use week-byweek during live courses, for MOOCs where this level of detail is available. The data collected by courses only focused upon levels of use during the periods which the course was active. Participation was defined in two ways; either by the number accessing course materials ('active students'), or the number who submitted assignments. Data about active students was available for 59 courses (figure 5), and those submitting assignments in 54 courses (figure 6). The sample included data from a range of courses and platforms, including 43 Open2Study courses (Open2Study, 2013), 17 Coursera courses (Belanger, 2013; Duke University, 2012; Grainger, 2013; University of Edinburgh, 2013; Severance, 2013); one edX course (Breslow et al., 2013); and two platform-independent courses (Cross, 2013; Weller, 2013). Note that the majority of 
courses included in figures 5, 6 and 7 were four weeks long due to the open availability of data from the Open2Study platform, upon which all courses are four weeks in duration.

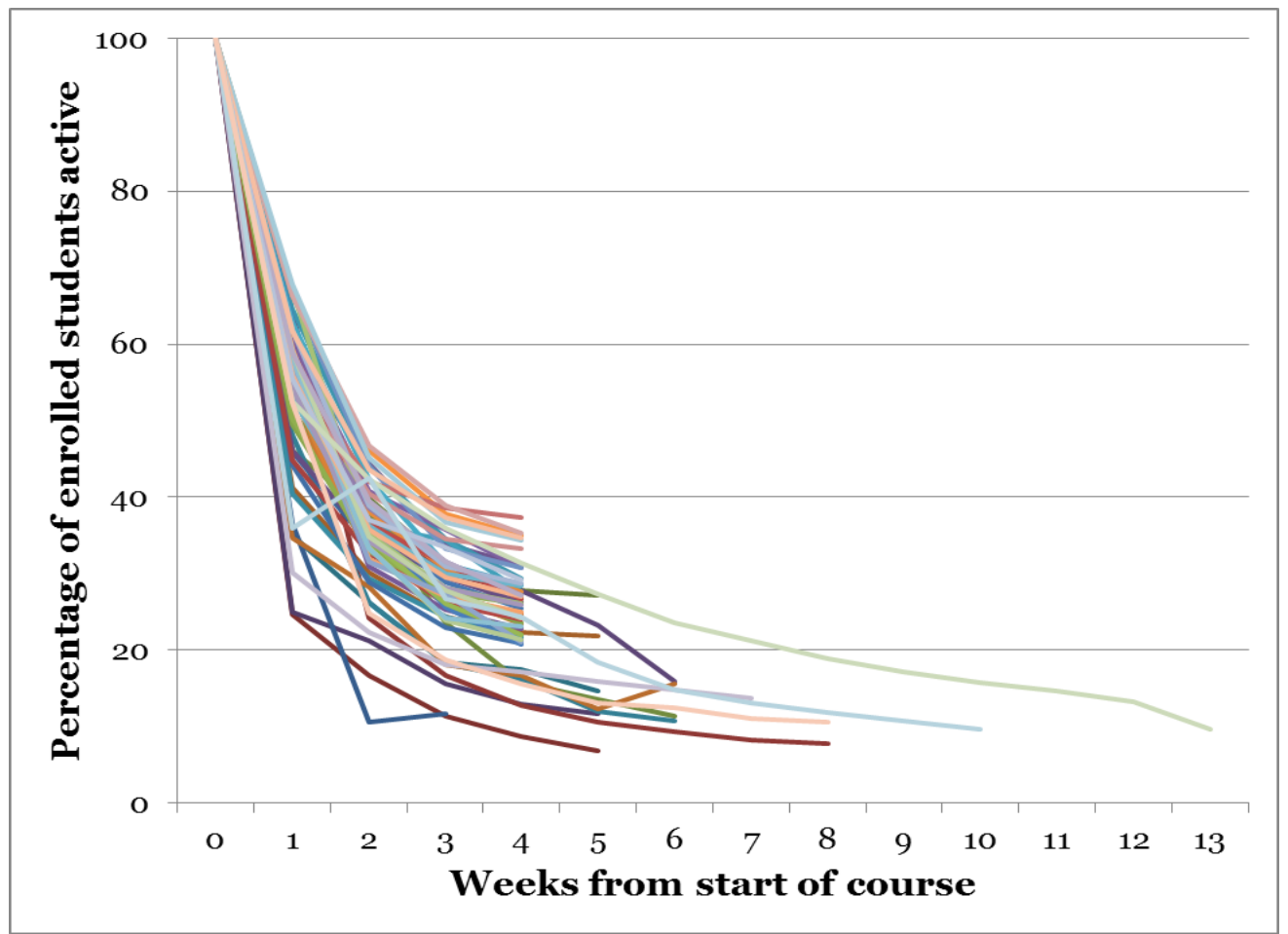

Figure 5. Proportion of active students (accessing course materials) per week since start of course as a percentage of total enrolment $(n=59)$. 


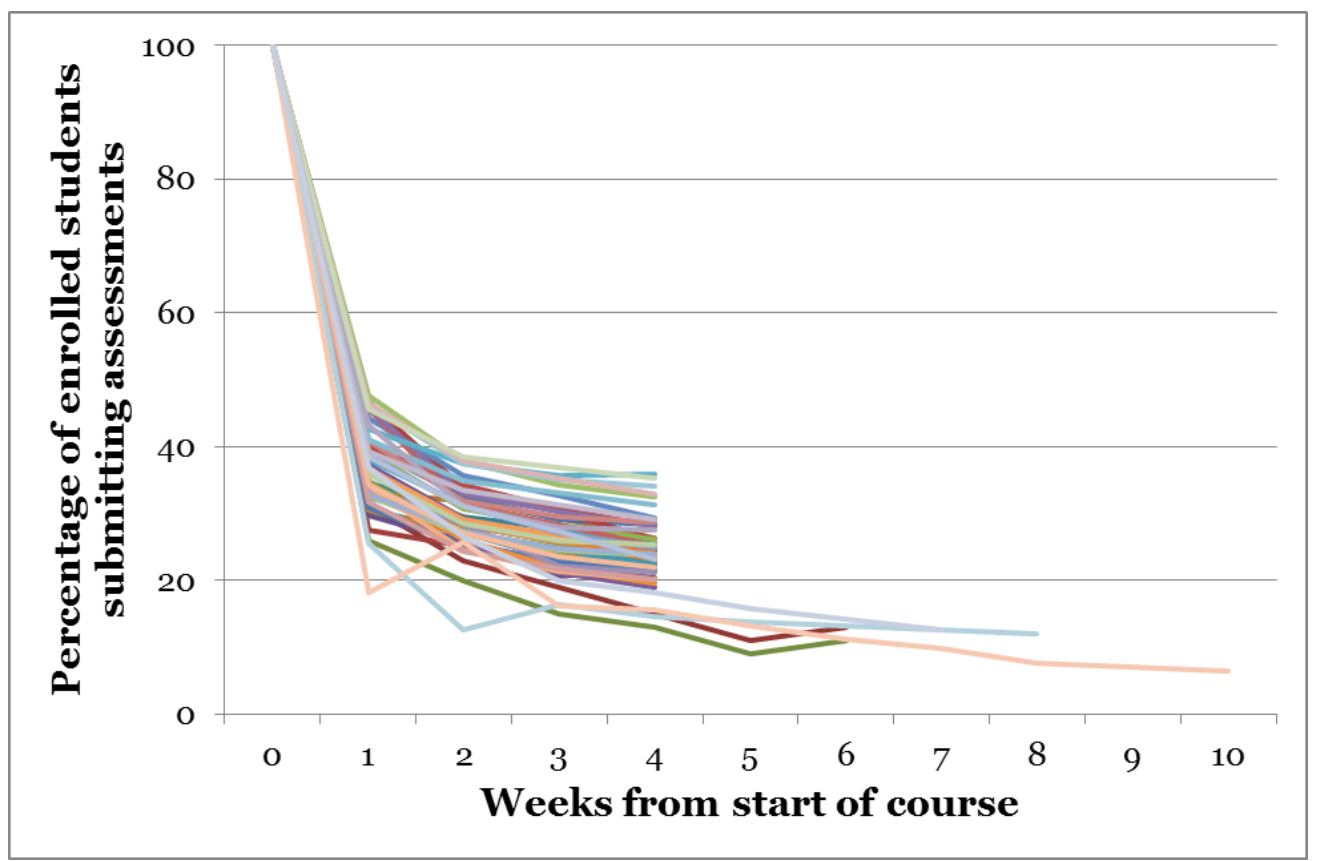

Figure 6. Proportion of students submitting assessments per week since start of courses as a percentage of total enrolment $(n=54)$.

The curves shown in Figures 5 and 6 are notable in two main ways. First, while the sample contains variety of different types of MOOCs (different platforms, institutions, and modes of teaching and assessment are present), the curves follow a similar overall trend. Around half of a MOOCs' enrolled students will not show up, and the first two weeks of a course appear to be critical in gaining student engagement. Second, after the first two weeks, there is little difference between the two measures of engagement - those accessing course materials and those submitting assignments. The difference between the two measures is shown in figure 7. After week 3 , the difference is less than five percent for all but two courses. This calls into question the extent to which lurking' (that is, selectively accessing course materials but not actively participating in assessments) is being used as a participation strategy, underlining the need for further research in this area. 


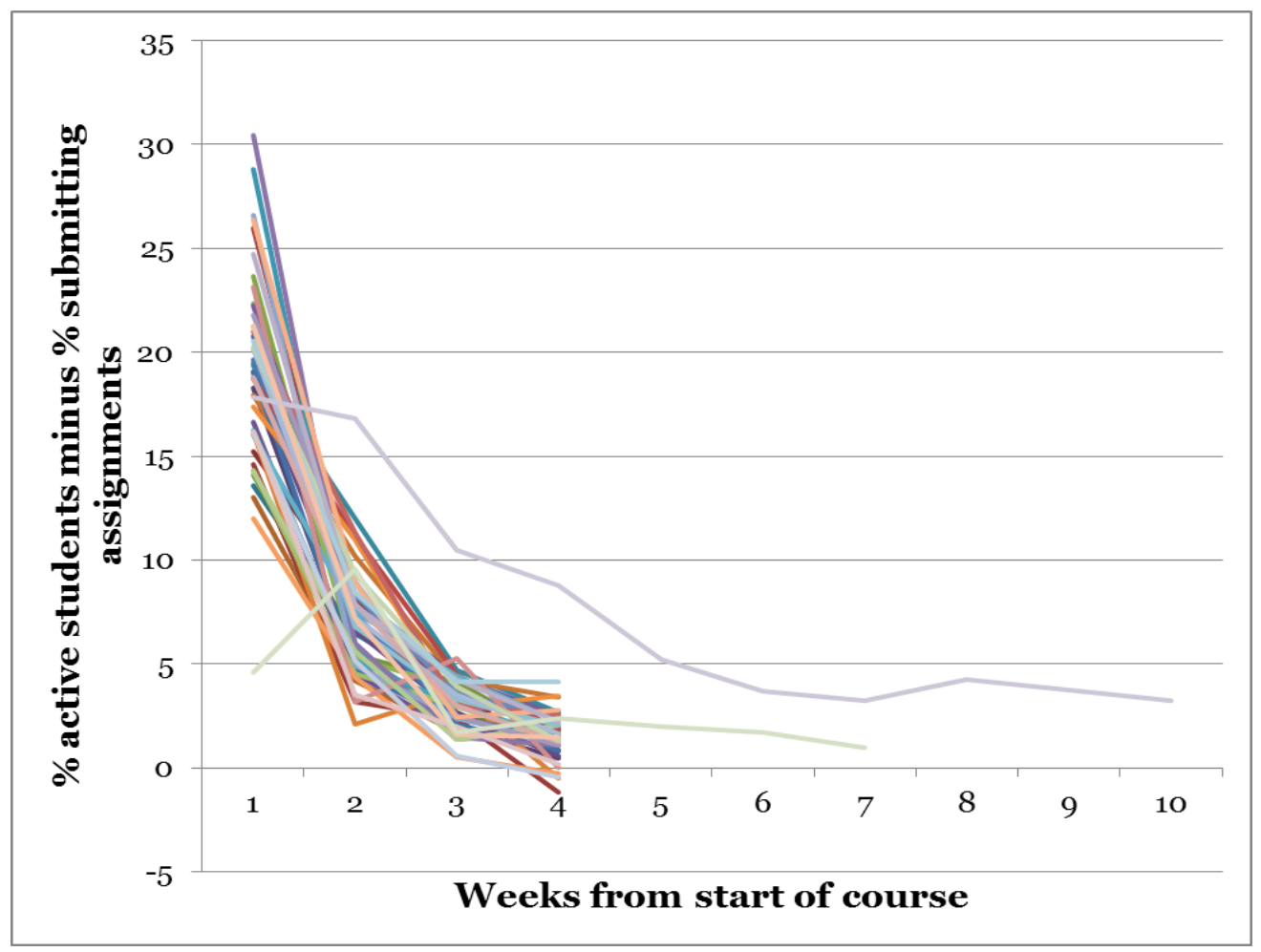

Figure 7. Difference between percentage of active students and percentage of students submitting assignments per week since the start of courses as a percentage of total enrolment $(n=50)$.

Note that since this work was undertaken, a similar study has been published based on rich, detailed data from 16 Coursera-based MOOCs provided by the University of Pennsylvania (Perna, Ruby, Boruch, Wang, Scull, Ahmad \& Evans, 2014). This study corroborates the findings here in that the initial weeks of courses are key for students engagement. Over the course of the MOOCs in the Perna et al. (2014) sample, broadly similar attrition curves are demonstrated, and the gap between students accessing materials and taking assignments narrows over time.

\section{Conclusions}

The multiple regression analysis highlights that it may be possible to gain insights into the impacts of different aspects of MOOC course design by considering completion rate across a large sample of courses. The results here may be useful for educators to consider when designing MOOCs, although there are limitations to this study and further research would be valuable. 
Factors that significantly predicted completion rate included start date, course length and assessment type. Completion rates were positively correlated with start date; that is, more recent courses demonstrate higher percentage completion. This is likely due to a decrease in average total enrolments over time, but may also reflect feedback and iterative design of courses.

On the basis of the negative correlation with course length, coupled with the attrition observed in the initial weeks of courses, a case could be made for shorter, more modular courses. Greater signposting would be required between courses for those students looking to create a more substantial programme of learning. Shorter courses with better guidance about how they could be combined could also benefit those students who prefer to direct their own learning by making it easier to find the parts of a course that they value; this would also allow for these students' MOOC achievements to be recognised. Modularisation for MOOCs has already been suggested by some (for example, Bol cited in Harvard Magazine, 2013; Challen \& Seltzer, 2014); the evidence here provides an empirical rationale for such developments, and further research would be valuable to examine the effects in practice. Note that in contrast to this finding Perna et al. (2014) reported no relationship between course length and completion rate. Given the similarity between the attrition curves reported by Perna et al. and those presented here, it is likely that the lack of a negative correlation is due to small sample size (16 courses from a single institution and platform, several of which are included in the dataset here).

The negative correlation between use of peer grading for assessments and completion rate suggests that course designers should carefully consider whether to use this as an assessment mechanism, or whether automated assessments would meet their educational goals. For example, in the case of peer grading short essays using a rubric based on factual recall, similar results could be achieved using multiple choice questions. In contrast, larger, project-based peer graded assessments may yield more significant learning gains for the students who do complete them as they are arguably more demanding and there is an aspect of vicarious learning from assessing others, though the quality of this also requires empirical verification. Further research into the use of peer grading would be valuable to investigate the reasons behind this finding. For example, it could be hypothesised that the lower completion rate in courses using peer grading may be due to peer assessments being more rigorous, disengagement due to having to wait for feedback, or reasons why students may choose not to attempt them (such as proficiency in English, for example). Another possible factor influencing increased attrition in peer graded MOOCs may be disengagement from students from minority cultural backgrounds as MOOC students assessing their peers have been shown to give higher marks to students from their own country (Kulkarni, Koh, Le, Papadopoulos, Cheng, Koller \& Klemmer, 2013). A better understanding of these issues is needed to clarify the circumstances in which peer grading could be recommended.

While this study provides some insights into the potential impact of learning design decisions upon completion rates, it does have its limitations and further empirical work is required. The principal limitation of this work is the availability of data from courses. This sample only reflects 
courses for which data is publicly available; a more detailed picture would be possible if further data was made available. The definition of completion rate as a percentage of enrolled students may be over-simplistic and subject to wide variations in enrolments (Ho et al., 2014). More nuanced definitions have been called for to reflect the numerous ways students may interact with MOOCs (DeBoer et al., 2014). However, the fact remains that total enrolments and certificateearning completers are the statistics most frequently present in the public domain. As the body of academic literature related to MOOCs grows, the potential for more detailed and robust metaanalysis is likely to increase in the future.

\section{Acknowledgments}

This research was supported by a grant from the MOOC Research Initiative, funded by the Gates Foundation. 


\section{References}

Belanger, Y. (2013) IntroAstro : An intense experience. Duke University Libraries. Retrieved from http:// hdl.handle.net/ 10161/ 6679

Breslow, L., Pritchard, D. E., DeBoer, J ., Stump, G. S., Ho, A.D., \& Seaton, D. T. (2013). Studying learning in the worldwide classroom: Research into edX's first MOOC. Research and Practice in Assessment, 8, 13-25.

Challen, G. \& Seltzer, M. (2014) Enabling MOOC collaborations through modularity. Proceedings of the 2014 Learning with MOOCs Practitioner's Workshop. Retrieved from http:// blue.cse.buffalo.edu/papers/lwmoocs2014-mmoocs/

Cross, S. (2013). Evaluation of the OLDS MOOC curriculum design course: participant perspectives, expectations and experiences. OLDS MOOC Project, Milton Keynes. Retrieved from http:// oro.open.ac.uk/37836/

DeBoer, J ., Ho, A., Stump, G., \& Breslow, L. (2014). Changing “course:” reconceptualizing educational variables for massive open online courses. Educational Researcher, 43(2), 74-84.

Duke University (2012) Introduction to Genetics and Evolution, preliminary report. Duke Today. Retrieved from http:// today.duke.edu/node/ 93914

Emanuel, E. J . (2013). Online education: MOOCs taken by educated few. Nature, 503(342). doi.org/ 10.1038/503342a

Ferguson, R. \& Clow, D. (2015) Examining engagement: analysing learner subpopulations in massive open online courses (MOOCs). In 5th International Learning Analytics and Knowledge Conference (LAK15), 16- 20 March 2015, Poughkeepsie, NY, USA, ACM.

Field, A. (2009) Discovering statistics using SPSS, 3d ed. London: SAGE.

Grainger, B. (2013) Overview statistics for the International Programmes' Coursera MOOCs. University of London International Academy. Retrieved from : http:// www.londoninternational.ac.uk/ sites/default/files/governance/ltas13/ltas13.3 m ooc_statistics.pdf

Harvard Magazine (2013) What modularity means for MOOCs. Harvard Magazine, $5^{\text {th }}$ December 2013. Retrieved from http:// harvardmagazine.com/2013/12/ harvard-mit-onlineeducation-views-changing 
Ho, A. D., Reich, J ., Nesterko, S., Seaton, D. T., Mullaney, T., Waldo, J ., \& Chuang, I. (2014). HarvardX and MITx: The first year of open online courses (HarvardX and MITx Working Paper No. 1). Retrieved from: http:// papers.ssrn.com/sol3/papers.cfm?abstract_id=2381263

J ordan, K. (2014) Initial trends in enrolment and completion of massive open online courses. The International Review of Research in Open and Distance Learning, 15(1), 133-160.

J ordan, K. (2015) MOOC completion rates: The data. Retrieved from: http:// www.katyjordan.com/MOOCproject.html

Kizilcec, R. F., Piech, C., \& Schneider, E. (2013). Deconstructing disengagement: Analyzing learner subpopulations in massive open online courses. Third International Conference on Learning Analytics and Knowledge, LAK '13 Leuven, Belgium.

Koller, D., \&Ng, A. (2013). The online revolution: Education for everyone. Seminar presentation at the Said Business School, Oxford University, 28th J anuary 2013. Retrieved from http:// www.youtube.com/ watch?v=mQ-K-sOW4fU\&feature=youtu.be

Koller, D., Ng, A., Do, C., \& Chen, Z. (2013). Retention and intention in massive open online courses: In depth. Educause Review. Retrieved from http:// www.educause.edu/ ero/article/retention-and-intention-massive-open-onlinecourses-depth-0

Kulkarni, C., Koh, P. W., Le, H., Chia, D., Papadopoulos, K., Cheng, J ., Koller, D., \& Klemmer, S.R. (2013). Peer and self-assessment in massive online classes. ACM Transactions on Computer-Human Interactions, 9(4) Article 39.

LeBar, M. (2014) MOOCs - Completion is not important. Forbes. Retrieved from: http:// www.forbes.com/ sites/ccap/2014/ 09/ 16/ moocs-finishing-is-not-the-importantpart/

Open2Study (2013) Open2study Research Report, September 2013. Retrieved from https:// www.open2study.com/research/download/417

Perna, L.W., Ruby, A., Boruch, R.F., Wang, N., Scull, J ., Ahmad, S. \&Evans, C. (2014) Moving through MOOCs: Understanding the progression of users in Massive Open Online Courses. Educational Researcher 43(9), 421-432.

Reich, J . (2014) MOOC completion and retention in the context of student intent. Educause Review. Retrieved from http:// www.educause.edu/ero/article/ mooc-completion-andretention-context-student-intent 
Rohatgi, A. (2014) WebPlotDigitizer software tool. Retrieved from http://arohatgi.info/WebPlotDigitizer/

Rosé, C. P., Carlson, R., Yang, D., Wen, M., Resnick, L., Goldman, P., \& Sherer, J . (2014). Social factors that contribute to attrition in MOOCs. In Proceedings of the first ACM conference on Learning@ scale conference (pp. 197- 198). ACM.

Severance, C. (2012) Internet history, technology and security (IHTS). Retrieved from http:// www.slideshare.net/ fullscreen/ csev/ internet-history-technology-and-securitygrand-finale-lecture-20121001/ 7

Times Higher Education. (2013). World University Rankings 2013-2014. Retrieved from http:// www.timeshighereducation.co.uk/ world-university-rankings/

University of Edinburgh. (2013). MOOCs @ Edinburgh 2013 - Report \#1. Retrieved from http://hdl.handle.net/1842/6683

Weller, M. (2013). H18Open reflections. The Ed Techie blog. Retrieved from http:// nogoodreason.typepad.co.uk/no_good_reason/h817open/

(C) J ordan

\section{Athabasca University $\mathbf{a}$}

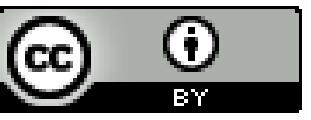

